\title{
Ocorrência de fungos micorrízicos arbusculares em um plantio de cupuaçu na estrada de Balbina, Amazonas
}

Cerca de $90 \%$ dos solos amazônicos são ácidos e de baixa fertilidade, pobres em nitrogênio e fósforo, além de apresentarem toxidez de alumínio, o que limita o seu uso na agricultura regional. Considerando-se o alto custo dos adubos e outros insumos, além das dificuldades de transporte pelos agricultores regionais, os sistemas agrícolas regionais precisam ser redirecionados com vistas a dar à população regional, maior independência em produtos básicos sem causar danos aos ecossistemas. Deste modo, associações micorrízicas do tipo arbuscular, constituem uma alternativa de grande importância para minimizar o uso de fertilizantes, por ajudarem as plantas a explorarem melhor o solo. Os benefícios da simbiose para o hospedeiro resultam de melhorias no estado nutricional da planta, melhor utilização e conservação de nutrientes no sistema, redução de perdas por estresses de natureza biótica ou abiótica. $O$ objetivo deste estudo melhorias no estado nutricional da planta, melhor utilização e conservação de nutrientes no sistema, redução de perdas por estresses de natureza biótica ou abiótica. 0 objetivo deste estudo
foi avaliar o efeito do carvão vegetal, adubação química e orgânica do solo na colonização micorrizicas no cupuaçu. $O$ trabalho foi desenvolvido no Km 42 da estrada de Balbina em Presidente Figueiredo no Amazonas. Foram feitas duas coletas de folhas, raízes e solos, uma na época da seca e outra na das chuvas, usando quatro tratamentos com três repetições. Os fungos micorrízicos arbusculares foram avaliados pelo método de clareamento e coloração das raízes. O solo, nos tratamentos com calagem, apresentou maiores teores de Ca e Mg, mas sem reduzi os teores elevados de Al e acidez. A adubação com K e P elevou os teores desses elementos no solo e os de Fe e Zn, que devem estar presentes como traços nos adubos de $\mathrm{K}$ e $\mathrm{P}$ adicionados. As colonizações radiculares por fungos micorrízicos arbusculares foram baixas nas duas coletas realizadas, sendo menor na época chuvosa. A contribuição da simbiose plantas-fungos micorrízicos para a nutrição das plantas foi afetada, devido à baixa ocorrência dos fungos nas raízes. Esporos do gênero Glomus sp foram os que mais ocorreram nos solos, seguidos pelos do gênero Scutellospora sp.

Palavras-chave: Colonização micorrízica; Glomus sp; Scutellospora sp.

\section{Occurrence of arbuscular mycorrhizal fungi in a cupuaçu plantation on the road to Balbina, Amazonas}

\begin{abstract}
About $90 \%$ of the Amazonian soils are acid and of low fertility, low in nitrogen and phosphorus, also having aluminum toxicity, which limits their use in regional agriculture. Considering the high cost of fertilizers and other inputs, in addition to transportation difficulties by regional farmers, regional farming systems need to be redirected in order to give the regional population greater independence in commodities without causing damage to ecosystems. Thus, plants associations with arbuscular mycorrhizal fungi (AMFs) constitute an alternative of great importance to minimize the use of fertilizers, since they help plants to explore the soils better. The benefits of this symbiosis for the host result of improvements in the nutritional status of the plant, to minimize the use of fertilizers, since they help plants to explore the soils better. The benefits of this symbiosis for the host result of improvements in the nutritional status of the plant,
better utilization and conservation of nutrients in the system, reducing losses by stresses of biotic or abiotic nature. The objective of this study was to evaluate the effect of charcoal, chemical better utilization and conservation of nutrients in the system, reducing losses by stresses of biotic or abiotic nature. The objective of this study was to evaluate the effect of charcoal, chemical fertilizer and organic soil in mycorrhizal colonization of cupuassu. The study was conducted at $\mathrm{Km} 42$ of Balbina road in Presidente Figueiredo Amazonas. Two harvest samples were made
with leaves, roots and soils, one in the dry season and another one in the rainy, using four treatments with three replications. The AMF were evaluated by the bleaching method and coloring the roots. The soil, with liming, had higher $\mathrm{Ca}$ and $\mathrm{Mg}$, but without reducing the high levels of $\mathrm{Al}$ and acidity. Fertilization with $\mathrm{K}$ and $\mathrm{P}$ raised the levels of these elements in the soil and the $\mathrm{Fe}$ and $\mathrm{Zn}$, which should be present as traces in $\mathrm{P}$ and $\mathrm{K}$ fertilizer added. The root colonization by AMF were low in the two surveys carried out, being lower in the rainy season. The contribution of mycorrhizal fungi symbiosis plants, for plant nutrition was affected due to low occurrence of fungi in the roots. Spores of the genus Glomus sp were the ones that occurred in soils, followed by the genus Scutellospora sp.
\end{abstract}

Keywords: Mycorrhizae colonization; Glomus sp; Scutellospora sp.

Topic: Microbiologia Agrícola e Ambiental

Reviewed anonymously in the process of blind peer.
Received: 09/02/2020

Approved: 06/03/2020
Luzia Pontt Melo Rocha (id)

Instituto Nacional de Pesquisas da Amazônia, Brasil http://lattes.cnpq.br/0319021830732034

http://orcid.org/0000-0003-0422-7360

luzipontt@gmail.com

Francisco Wesen Moreira (iD)

Instituto Nacional de Pesquisas da Amazônia, Brasil

http://lattes.cnpq.br/1416538021119110

http://orcid.org/0000-0002-8763-254X

wesen@inpa.gov.br

Cassiane Minelli de Oliveira (it)

Universidade Paulista, Brasil

http://lattes.cnpq.br/3681043451620632

http://orcid.org/0000-0003-4827-9955

cassyminelli@gmail.com

d

DOI: 10.6008/CBPC2179-6858.2020.002.0009
Luiz Antonio de Oliveira (iD)

Instituto Nacional de Pesquisas da Amazônia, Brasil

http://lattes.cnpq.br/9931395111001102

http://orcid.org/0000-0002-2008-7292

luiz.oliveira@inpa.gov.br
Referencing this:

ROCHA, L. P. M.; MOREIRA, F. W.; OLIVEIRA, C. M.; OLIVEIRA, L. A.. Ocorrência de fungos micorrízicos arbusculares em um plantio de cupuaçu na estrada de Balbina, Amazonas. Revista Ibero Americana de Ciências Ambientais, v.11, n.2, p.78-84, 2020. DOI: http://doi.org/10.6008/CBPC2179-6858.2020.002.0009 


\section{INTRODUÇÃO}

A Comunidade São Jorge, no Km 42 da estrada de Balbina em Presidente Figueiredo no Estado do Amazonas, é composta de pequenas propriedades rurais, a maioria com famílias de baixa renda. Por isso, poucos usam insumos agrícolas, como adubos e defensivos. Devido a isso, a produtividade é baixa, uma vez que nesses solos, as limitações são de ordem química, pois a maioria, classificada como Latossolos e Podzólicos (Oxisols e Ultisols), além de serem ácidos e de baixa fertilidade, apresentam toxidez de alumínio (SANCHEZ et al., 1982; NICHOLAIDES et al., 1983; MALAVOLTA, 1987; EMBRAPA, 1990; TUCCI, 1991).

O uso de espécies de importância econômica como o cupuaçu e muito comum nas propriedades rurais do Estado do Amazonas e podem ser um fator de desenvolvimento para o Estado e uma fonte de renda para os produtores. Deste modo, associações micorrízica do tipo arbuscular, constituem uma alternativa de grande importância para se minimizar o uso de fertilizantes, por ajudarem as plantas a explorarem melhor o solo (OLIVEIRA, 1991; SIQUEIRA et al., 2002). As associações micorrízicas arbusculares são componentes importantes dos ecossistemas e desempenham papel crucial para sua funcionalidade e sustentabilidade. Os benefícios da simbiose para o hospedeiro resultam de melhorias no estado nutricional da planta, melhor utilização e conservação de nutrientes no sistema, redução de perdas por estresses de natureza biótica ou abiótica (BALOTA et al., 1994).

No Estado do Amazonas praticamente não existe atividade agrícola que responda adequadamente à demanda das populações urbanas (SEPROR, 1991). Os sistemas agrícolas regionais precisam ser redirecionados com vistas a dar à população regional, maior independência em produtos básicos sem causar danos aos ecossistemas (OLIVEIRA, 1991b).

Considerando-se o alto custo dos adubos e outros insumos, além das dificuldades de transporte pelos agricultores regionais, métodos alternativos de fertilização devem ser buscados, visando um manejo mais racional e econômico dos recursos naturais. Deste modo, o aproveitamento das potencialidades das associações micorrízicas é uma alternativa de grande importância para aumentar a disponibilidade de nutrientes e sua absorção pelas plantas. Essas associações poderão trazer um aumento no potencial produtivo das plantas nestes sistemas de produção, com baixos insumos, tornando-os bem-sucedidos na região, demonstrando a importância destes microrganismos.

Deste modo, este projeto enfatiza a necessidade de mais pesquisas para que se compreenda melhor o funcionamento destas associações, permitindo que sejam eficazes e auxiliem na viabilidade ecológica e econômica desta tão importante e vasta região. Pesquisas neste sentido poderão proporcionar material genético adaptado às condições regionais e informações científicas de grande contribuição para os sistemas agroflorestais implantados na Amazônia.

O objetivo deste trabalho foi avaliar as taxas de colonização por fungos micorrízicos arbusculares nas raízes das plantas, bem como, quantificar os esporos micorrízicos nos solos rizosféricos, determinar as características químicas dos solos e determinar os teores de macro e micronutrientes nos tecidos foliares das plantas. 


\section{MATERIAIS E MÉTODOS}

O projeto foi desenvolvido na comunidade São Jorge, no Km 42 da estrada de Balbina Presidente Figueiredo no Amazonas. A espécie estudada foi o cupuaçu. Foram realizadas duas coletas de folhas, raízes e solos, uma na época da seca (agosto-setembro) e outra na época das chuvas (janeiro-fevereiro). Foram usados quatro tratamentos por planta com três repetições: 1. CONTROLE; 2. FORMULAÇAO NPK + CALCARIO DOLOMITICO + MICRONUTRIENTE; 3. CARVÃO + FORMULAÇAO NPK; 4. CARVÃO + ESTERCO DE GADO + FORMULAÇAO NPK.

Os fungos micorrízicos arbusculares foram avaliados pelo método de Kormanick et al. (1980) e pelas metodologias descritas em Schenck (1982). Essas metodologias consistem no clareamento (KOH 10\%) e coloração das raízes (azul de tripano). As colonizações radiculares foram avaliadas utilizando-se o método da lâmina, dispondo-se de 50 segmentos de raiz por planta, cada um com aproximadamente $1 \mathrm{~cm}$ de comprimento e analisadas em microscópio.

As amostras de solos foram retiradas da rizosfera de cada planta, à profundidade de $0-10 \mathrm{~cm}$, sendo submetidas a análises químicas descritas em Vettori (1967) e Embrapa (1997) no laboratório do INPA. A análise química consistiu das seguintes metodologias: $\mathrm{pH}(\mathrm{H} 2 \mathrm{O}), \mathrm{Ca}, \mathrm{Mg}$ e $\mathrm{Al}(\mathrm{KCl} 1 \mathrm{~N}), \mathrm{P}$ (extração pelo Mehlich e leitura por colorimetria), K, Mn, Zn e Fe (Mehlich 1, absorção atômica) e carbono pelo método de Walkley-Black.

As folhas foram retiradas segundo Van Den Driessche (1974) e separadas em três classes: das extremidades dos ramos (novas), intermediárias ou medianas (médias) e basais (velhas), conforme Dall'orto et al. (1976), formando uma amostra composta para as determinações de macro e micronutrientes segundo Embrapa (1988). As folhas foram analisadas quimicamente quanto aos teores de macro e micronutrientes, usando-se a metodologia descrita em EMBRAPA (1988). As determinações foram feitas para o fósforo, potássio, cálcio, magnésio, ferro, zinco, cobre e manganês.

Foram coletadas amostras de solos $(30 \mathrm{~g})$ para o procedimento da contagem de esporos de fungos MA segundo a técnica de peneiramento úmida descrita por Gerdemann et al. (1963) e Schenck (1982). A técnica consiste na utilização de peneiras de $0,044 \mathrm{~mm}, 0,045 \mathrm{~mm}$ e $0,250 \mathrm{~mm}$ de abertura, nesta ordem consecutiva. Para a contagem de esporos foi utilizada uma lupa, com aumentos de 1,5X e 4,5X.

O delineamento experimental adotado foi o inteiramente casualizado (DIC). Foram realizadas as análises estatísticas dos dados, empregando-se o teste de Tukey ao nível de 5\% de probabilidade para estabelecer as diferenças entre as médias dos tratamentos que se mostraram diferentes pelo teste $F$ (GOMEZ et al., 1984), bem como as análises de regressão simples para a determinação do grau de correlação entre as colonizações por fungos micorrízicos nas raízes e teores de macro e micronutrientes nas folhas.

\section{RESULTADOS E DISCUSSÃO}

Os solos de Presidente Figueiredo mostraram ser ácidos. Os teores de Ca foram médios e baixos, mesmo no tratamento onde se aplicou calcário, indicando que o efeito desse corretivo já desapareceu, sendo 
que no tratamento testemunha, o solo apresentou maiores teores de $\mathrm{Ca}$ e $\mathrm{Mg}$. A falta de efeito da calagem pode se comprovada pelos teores elevados de Al. Quanto ao K, somente o solo do tratamento testemunha apresentou níveis elevados, segundo Cochrane et al. (1995). Os teores de P foram considerados muitos elevados nos tratamentos onde houve adubação com esse elemento, indicando que ainda há no solo, fósforo residual disponível para as plantas. Quanto aos teores de Fe e Zn, o solo exibiu resultados altos e satisfatórios respectivamente.

Tabela 1: Teores de nutrientes dos solos amostrados de Presidente Figueiredo em Balbina.

\begin{tabular}{|c|c|c|c|c|c|c|c|c|}
\hline Tratamento & $\mathrm{pH}\left(\mathrm{H}_{2} \mathrm{O}\right)$ & $\mathrm{Ca}++$ & $\mathrm{Mg}++$ & $\mathrm{Al+++}$ & $\mathrm{K}+$ & $\mathrm{P}$ & $\mathrm{Fe}$ & $\mathrm{Zn}$ \\
\hline & \multicolumn{8}{|c|}{ 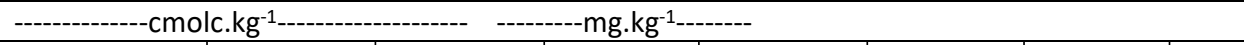 } \\
\hline Testemunha & 4,4B & $0,90 \mathrm{M}$ & $0,63 \mathrm{M}$ & $1,54 \underline{a}$ & $0,38 \mathrm{~A}$ & $0,24 B$ & $125 \mathrm{~A}$ & $16 \mathrm{~S}$ \\
\hline $\begin{array}{l}\text { NPK + Calcário } \\
+ \text { Micronutriente }\end{array}$ & $4,1 \mathrm{~B}$ & $0,28 \mathrm{~B}$ & $0,03 B$ & $1,55^{\mathrm{a}}$ & $0,14 \mathrm{~B}$ & $1,61 B$ & $181 \mathrm{~A}$ & 475 \\
\hline Carvão + NPK & $4,3 \mathrm{~B}$ & $0,34 \mathrm{~B}$ & $0,04 \mathrm{~B}$ & $1,64 \underline{a}$ & $0,17 \mathrm{M}$ & $12,6 \mathrm{~A}$ & $172 \mathrm{~A}$ & $37 S$ \\
\hline $\begin{array}{l}\text { Carvão + Esterco } \\
\text { de gado + NPK }\end{array}$ & $4,5 B$ & $0,41 \mathrm{M}$ & $0,08 \mathrm{~B}$ & $1,59 \mathrm{a}$ & $0,21 \mathrm{M}$ & $9,6 \mathrm{~A}$ & $158 \mathrm{~A}$ & $172 \mathrm{~S}$ \\
\hline
\end{tabular}

Classificação dos valores segundo Cochrane et al. (1985) A= alto; B= baixo; M= médio; S=(satisfatório).

Ao se analisar os teores de elementos nas folhas (Tabela 2), não se observaram diferenças das adubações em comparação com as plantas testemunhas quanto ao $\mathrm{Ca}, \mathrm{K}, \mathrm{P}$ e Fe. Observou apenas que as plantas do tratamento testemunha se apresentavam com teores mais elevados de $\mathrm{Mg}$ do que as adubadas com NPK e micronutrientes e onde foi aplicado o calcário. Essa menor concentração de Mg nas plantas adubadas pode ser um reflexo de um maior desenvolvimento das plantas, e como elas não foram adubadas com esse elemento, houve uma diluição dele nos tecidos foliares. Por outro lado, as plantas da testemunha apresentaram menores teores de Zn do que as adubadas com esterco, NPK com a adição de carvão, sugerindo que esse microelemento estivesse como traços em algum dos adubos ou calcário colocados, principalmente no esterco de gado.

Tabela 2: Teores de macro e micronutrientes das folhas do cupuaçu de uma propriedade rural de Presidente Figueiredo.

\begin{tabular}{|c|c|c|c|c|c|c|}
\hline Tratamento & $\mathrm{Ca}++$ & $\mathrm{Mg++}$ & $\mathrm{K}+$ & $\mathrm{P}$ & $\mathrm{Fe}$ & $\mathrm{Zn}$ \\
\hline & \multicolumn{4}{|c|}{----------------g.kg---------------- } & \multicolumn{2}{|c|}{----------mg.kg----------- } \\
\hline Testemunha & 5,17 & $2,48 a$ & 4,47 & 8,76 & 32 & $24 \mathrm{~b}$ \\
\hline NPK + Calcário + Micronutrientes & 6,81 & $2,09 \mathrm{~b}$ & 3,62 & 11,35 & 34 & $29 a b$ \\
\hline Carvão + NPK & 6,22 & $2,20 \mathrm{ab}$ & 3,73 & 11,03 & 26 & $30 a b$ \\
\hline Carvão + Esterco de gado + NPK & 5,63 & $2,29 a b$ & 4,50 & 11,53 & 35 & $33 a$ \\
\hline $\mathrm{CV} \%$ & 21,71 & 11,49 & 20,22 & 20,08 & 21,02 & 22,76 \\
\hline
\end{tabular}

As médias com letras iguais não diferem estatisticamente pelo teste de Tukey a $5 \%$ de probabilidade.

A colonização radicular por fungos micorrízicos arbusculares foi favorecida pelas adubações quando comparadas com as da testemunha (Tabela 3). Isso pode ser observado tanto para as hifas quanto para as vesículas, o que se refletiu positivamente na colonização radicular total.

Tabela 3: Colonização por fungos micorrízicos arbusculares em plantio de cupuaçu no período seco (setembro de 2011).

\begin{tabular}{|c|c|c|c|}
\hline Tratamentos & Hifas & Ves. & Col. total \\
\hline & \multicolumn{3}{|c|}{------------ \% ------------- } \\
\hline Testemunha & 7,6 & 2,3 & 10,0 \\
\hline NPK + Calcário + Micronutriente & 16,6 & 9,8 & 26,6 \\
\hline Carvão + NPK & 22,2 & 20,9 & 32,5 \\
\hline Carvão + Esterco de gado + NPK & 21,8 & 6,8 & 25,3 \\
\hline
\end{tabular}


Na coleta realizada em setembro de 2011 (Tabela 3), período considerado como da época seca na região, as colonizações radiculares por FMA variaram de 10,0 a 32,5\% com as presenças de hifas variando de 7,6 a 22,2\% e vesículas de 2,3 a 20,9\%. As plantas do tratamento com carvão mais NPK foram as que tiveram os maiores índices de colonização micorrízica, enquanto as da testemunha apresentaram o menor índice de colonização micorrízica nessa época.

Nesse período, as plantas têm dificuldades em obter nutrientes do solo, o que pode ser facilitado pela maior presença de hifas que vesículas. Na simbiose, as hifas servem para captar nutrientes e água do solo e as vesículas como estruturas de reservas do fungo. No entanto, os índices de colonização radicular por FMA ainda são baixos na maioria dos tratamentos e pouco ou nada devem contribuir para a nutrição dessas plantas. Apesar disso, os tratamentos com NPK apresentaram índices superiores a $20 \%$ de colonização radicular total de FMA, indicando que as plantas devem estar sendo beneficiadas pela simbiose.

Na coleta realizada em janeiro de 2012 (Tabela 4), as colonizações radiculares por FMA variaram de 1,5 a 4,2\%, com as presenças de hifas variando de 1,1 a 3,4\%, vesículas de 0,4 a $0,8 \%$ e não houve presença de arbúsculos. Era de se esperar, portanto, que houvesse maiores índices de colonização micorrízica, pois seria um período propício para a emissão de novas raízes finas e absorção de água e nutrientes pelas plantas. Algum fator ligado ao solo, às plantas e aos fungos, bem como à interação entre os três pode ter afetado negativamente a colonização radicular pelos FMA.

Tabela 4: Colonização por fungos micorrízicos arbusculares em plantio de cupuaçu no período chuvosa (janeiro de 2012).

\begin{tabular}{|c|c|c|c|}
\hline Tratamentos & Hifas & Ves. & Col. total \\
\hline & \multicolumn{3}{|c|}{----------- \% ------------ } \\
\hline Testemunha & 3,4 & 0,8 & 4,2 \\
\hline NPK + Calcário + Micronutriente & 1,8 & 0,7 & 2,5 \\
\hline Carvão + NPK & 1,1 & 0,4 & 1,5 \\
\hline Carvão + Esterco de gado + NPK & 1,5 & 0,7 & 2,2 \\
\hline
\end{tabular}

Por isso os baixos percentuais de colonização micorrízica estão associados ao pequeno número de plantas que formaram hifas e vesículas durante essa época, embora, as plantas amostradas tenham sido as mesmas das coletas anteriores. Nenhuma das plantas dos tratamentos amostrados está sendo beneficiada significativamente pela simbiose nessa época de amostragem, devido aos baixos índices de colonização micorrízica nas raízes. Por isso, os fungos micorrízicos arbusculares perdem essa função e passam a desenvolver mecanismos para o processo de produção de esporos, fase que procede a formação de vesículas.

\section{Quantidade e diversidade de esporos}

Houve diferença significativa entre os tratamentos na porcentagem de esporos de Scutellospora sp, enquanto que para Acaulospora sp, Gigaspora sp e Glomus sp as médias não diferiram estatisticamente. 0 número médio de esporos por $30 \mathrm{~g}$ de solo variou de 3,6 a 9,6 nos de Acaulospora sp, 0,4 a 1,4 nos de Gigaspora sp, 89,7 a 156,6 de Glomus sp e 16,5 a 35,5 para os de Scutellospora sp (Tabela 5).

O gênero Glomus sp foi dominante e apresentou a maior média $(114,7$ esporos/30g solo, enquanto os gêneros Acaulospora sp e Gigaspora sp apresentaram poucos esporos no solo, com o gênero Scutellospora 
sp com um número intermediário (25 esporos em $30 \mathrm{~g}$ de solo (Tabela 5). Da mesma forma que para colonização micorrízica (Tabela 5), não há suficientes estudos publicados na literatura nacional que relacionem densidade e diversidade de esporos de FMAs em solo rizosférico de cupuaçu. De acordo com Silva et al. (2009; 2015), o conhecimento da diversidade das populações de FMAs, bem como de seu papel e das interações com o meio abiótico, é requisito fundamental para explicar o crescimento de plantas micorrizadas. O estudo da diversidade revela aspectos ligados à sobrevivência e persistência de espécies em determinado ambiente ou rizosfera, podendo ser usado na avaliação dos efeitos benéficos da simbiose e dos impactos do manejo agrícola e ambiental aplicado nessa cultura.

Tabela 5: Quantidade e diversidade de esporos de fungos micorrízicos arbusculares obtidos na rizosfera de cupuaçu no período seco (setembro de 2011).

\begin{tabular}{|c|c|c|c|c|}
\hline Tratamentos & Acaulospora & Gigaspora & Glomus & Scutellospora \\
\hline & \multicolumn{4}{|c|}{---- numero de esporos/30g solo ------------ } \\
\hline Testemunha & $3,6 a *$ & $0,4 a$ & $115,2 \mathrm{a}$ & $28,4 a b$ \\
\hline NPK + Calcário + Micronutriente & $4,5 a$ & $0,5 a$ & $89,7 a$ & $16,5 \mathrm{~b}$ \\
\hline Carvão + NPK & $4,3 a$ & $0,5 a$ & $97,6 a$ & $19,6 \mathrm{~b}$ \\
\hline Carvão + Esterco de gado + NPK & 9,6aa & $1,4 a$ & $156,6 a$ & $35,5 a$ \\
\hline Médias & 5,5 & 0,7 & 114,7 & 25,0 \\
\hline
\end{tabular}

Médias seguidas por letras iguais nas colunas não diferem estatisticamente entre si pelo o teste de Tukey ao nível de $5 \%$ de probabilidade. *Médias de três blocos com três repetições.

Ao se analisar os dados obtidos na coleta de janeiro de 2012 (Tabela 6), observou-se o mesmo comportamento ocorrido em setembro, com predominância de esporos do gênero Glomus seguido pelos do Scutellospora. Mas nessa coleta, os tratamentos interferiram significativamente nos números de esporos dos gêneros Acaulospora sp, Glomus sp e Scutellospora sp, enquanto que os de Gigaspora sp não foram afetados pelas adubações e calagem. O número médio de esporos por $30 \mathrm{~g}$ de solo variou de 7,3 a 16,0 nos de Acaulospora sp, 0,0 a 0,4 nos de Gigaspora sp, 42,0 a 86,2 de Glomus sp e 20,6 a 33,3 para os de Scutellospora sp (Tabela 6).

Tabela 6. Quantidade e Diversidade de esporos de fungos micorrízicos arbusculares obtidos na rizosfera de cupuaçu no período chuvoso (janeiro de 2012).

\begin{tabular}{|l|l|l|l|l|}
\hline Tratamentos & Acaulospora & Gigaspora & \multicolumn{1}{|l|}{ Glomus } & \multicolumn{1}{l|}{ Scutellospora } \\
\hline & & \multicolumn{2}{|l}{--- - numero de esporos/30g solo ----- } \\
\hline Testemunha & $7,3 \mathrm{~b}^{*}$ & $0,2 \mathrm{a}$ & $\mathbf{4 2 , 0} \mathrm{b}$ & $24.3 \mathrm{ab}$ \\
\hline NPK + Calcário + Micronutriente & $13,1 \mathrm{ab}$ & $0,4 \mathrm{a}$ & $59,1 \mathrm{ab}$ & $20,6 \mathrm{~b}$ \\
\hline Carvão + NPK & $9,3 \mathrm{ab}$ & $0,2 \mathrm{a}$ & $50,5 \mathrm{~b}$ & $23,1 \mathrm{ab}$ \\
\hline Carvão + Esterco de gado + NPK & $16,0 \mathrm{a}$ & $0,0 \mathrm{a}$ & $86,2 \mathrm{a}$ & $33,3 \mathrm{a}$ \\
\hline Médias & $\mathbf{1 1 , 4}$ & $\mathbf{0 , 2}$ & $\mathbf{5 9 , 4}$ & $\mathbf{2 5 , 3}$ \\
\hline
\end{tabular}

Médias seguidas por letras iguais não diferem estatisticamente entre si pelo o teste de Tukey ao nível de $5 \%$ de probabilidade. *Médias de três blocos com três repetições.

\section{CONCLUSÕES}

A adubação e calagem não resultaram em elevação do pH e nem redução do $\mathrm{Al}$, mas aumentaram os teores de K, P, Zn e Fe nos solos. A adubação e calagem reduziram os teores de Mg e aumentaram os de Zn nas folhas do cupuaçu. As colonizações radiculares por fungos micorrízicos arbusculares foram baixas nas duas coletas realizadas, sendo menor na época chuvosa. A contribuição da simbiose plantas-fungos micorrízicos para a nutrição das plantas foi afetada, devido à baixa ocorrência dos fungos nas raízes. Esporos 
do gênero Glomus sp foram os que mais ocorreram nos solos, seguidos pelos do gênero Scutellospora sp.

AGRADECIMENTOS: ao Conselho Científico de Desenvolvimento Científico e Tecnológico (CNPq) e Fundação de Amparo à Pesquisa do Estado do Amazonas (FAPEAM) pelo apoio financeiro para a realização dessa pesquisa.

\section{REFERÊNCIAS}

BALOTA, E. L.; COLOZZI-FILHO, A.. Micorrizas arbusculares. In: Manual de Métodos Empregados em Estudos de Microbiologia Agrícola. Brasília: Embrapa, 1994. p.384-418.

DALL'ORTO, F. A. C.; GARLIPP, R. C. D.; BRAUNER, L. J.; MIRANDA, M. T.. Concentrações de algum macro e micronutrientes em essências florestais do parque da Escola Superior de Agricultura Luiz de Queiroz, Anais da E. S. A. Luiz de Queiroz, v.33, p.233-242, 1976.

EMBRAPA. Análise foliar: laboratório de análises de solos e plantas. Manaus: Centro Nacional de Pesquisas de Seringueira e Dendê, 1988.

EMBRAPA. A questão agrícola da Amazônia: aptidão das terras. Belém: Embrapa, 1990.

EMBRAPA. Manual de métodos de análise de solos. 2 ed. Serviço Nacional de Levantamento e Conservação do Solo. Rio de Janeiro: EMBRAPA, 1997.

GERDEMANN, J. W.; NICOLSON, T. H.. Spores of mycorrhizal endogone species extracted from soil by wet sleving and decating. Trans. Br. Mycol. Soc., v.46, p.235-244, 1963.

GOMEZ, K. A.; GOMEZ, A. A.. Statistical procedures for agricultural research. 2 ed. New York: John Wiley \& Sons, 1984.

KORMANIK, P. P.; BRYAN, W. C.; SCHULTZ, R. C.. Procedures and equipment for staining large numbers of plant root samples for endomycorrhizal assay. Can. J. Microbiol., v.26, p.536-538, 1980.

NICHOLAIDES, J. J.; SANCHEZ, P. A.; BANDY, D. E.; VILLACHICA, J. H.; COUTU, A. J.; VALVERDE, C. S.. Crop production systems in the Amazon Basin. In: MORAN, E.. The dilemma of Amazonia Development. Westview, 1983. p.101-153.

OLIVEIRA, L. A.. Phosphorus related to plant growth and plant-microorganism associations in amazonian soils. In: TIESSEN, H.; LÓPEZ-HERNANDEZ, D.; SALCEDO, I. H.. Phosphorus Cycles in Terrestrial and Aquatic Ecosystems. Regional Workshop 3: South and Central America, Maracay, 1991a. p.186-195.

OLIVEIRA, L. A.. Ocupação racional da Amazônia: o caminho para preservar. In: VAL, L. A.; FIGLIUOLO, R.; FELDBERG, E.. Bases Científicas para Estratégias de Preservação e Desenvolvimento da Amazônia: Fatos e Perspectivas. 1991b. p.47-52.

SCHENCK, N. C.. Methods and Principles of Mycorrhizal Research. The Amer. Phytopat. Soc. Publ., St. Paul, MN, USA. 1982.

SILVA, G. A.; SILVA, G.; SIQUEIRA, O.; STÜRMER, S. L.. Eficiência de fungos micorrízicos arbusculares isolados de solos sob diferentes sistemas de uso na região do Alto Solimões na Amazônia. Acta Amazônica, v.477, p.477-488, 2009. DOI: http://doi.org/10.1590/S004459672009000300001

SILVA, R. F.; MARCO, R.; BERTOLLO, G. M.; MATSOUKA, M.; MENEGOL, D. R.. Influência do uso do solo na ocorrência e diversidade de FMAs em Latossolo no Sul do Brasil. Semina: Ciências Agrárias, v.36, n.3, p.1851-1862, 2015.

VAN DEN DRIESSCHE, H. K.. Prediction of mineral Nutrient status of trees by foliar analysis. The Bot. Rev., v.40, n.3, p.347-394, 1974.

A CBPC - Companhia Brasileira de Produção Científica (CNPJ: 11.221.422/0001-03) detém os direitos materiais desta publicação. Os direitos referem-se à publicação do trabalho em qualquer parte do mundo, incluindo os direitos às renovações, expansões e disseminações da contribuição, bem como outros direitos subsidiários. Todos os trabalhos publicados eletronicamente poderão posteriormente ser publicados em coletâneas impressas sob coordenação da Sustenere Publishing, da Companhia Brasileira de Produção Científica e seus parceiros autorizados. Os (as) autores (as) preservam os direitos autorais, mas não têm permissão para a publicação da contribuição em outro meio, impresso ou digital, em português ou em tradução. 